\title{
Appraisal of Storage and Collection Strategies of Municipal Solid Waste in Lagos State
}

\author{
Odewumi, S.G. (PhD) \\ Dept. of Geography \& Planning, Lagos State University, Nigeria
}

\begin{abstract}
Successive governments in Lagos State have had to contend with the problem of the management of Municipal Solid Waste. Various strategies have been deployed to tackle the problem with varying degree of successes. The objective of this paper is to appraise two aspects of this problem: Storage and Collection. The weaknesses and strengths of the methods were examined and the insights into these formed the bases of suggestions for improvement in the study area Primary data were obtained through interviews with the various stakeholders and secondary data were collated from the archives of relevant agencies, especially Lagos Waste Management Authority (LAWMA) and earlier study by the author. In Lagos state, waste storage is done at the point of generation and temporary mid-way locations like Refuse Houses, Community Dumpsites, Highway median, Junctions and Bus stops. Major refuse collection methods examined include: bell ringing, Door-toDoor/Highway Traverse, Bulk-loading, Vehicle towing, Corpse removals and Bin Collections. Major suggestions made are concerned with the need for sorting of the waste at the point of generation to enhance reduction, re-use and re-cycling which will provide jobs, income, raw materials and promote clean environment. Refuse Houses that were sold off should be re-purchased for the use of the PSP operators as temporary storage point. It is also suggested that demographic characteristics and activities be understood before any storage or collection strategy is adopted. Government is advised to continue with its involvement of private sector participants with appropriate legal, infrastructural and institutional support. It is also suggested that public enlightenment be continuous to inform the residents of the government's policy and the duties and privileges of the citizens thereof.
\end{abstract}

Keywords: collection of solid waste, storage of solid waste, lawma

\section{Introduction}

As a result of rapid population growth and her status as commercial and industrial hub of Nigerian economy the problem of municipal solid waste management has always been a run-away phenomenon. This is true for all the governments that ever rule Lagos State at whatever level -federal, State, local-and in any dispensationmilitary or democratic. The State has the reputation of being the dirtiest capital in the world (Guinness Book of Records 1983). Consequently a lot of experimentation has taken place in the overall management strategies. It is a perpetual convergence point of incubation and cemetery of ideas in general and in the areas of storage and collection of municipal solid waste (MSW) in particular in the state. The objectives of this paper includes the profiling of the adopted methods of solid waste storage and collection in the state; examining the basis of their adoption and the factors responsible for jettisoning of some; evaluate their suitability, suggest options and modifications as considered appropriate. The weaknesses and strengths of the system will be discussed and the insights into these will form the bases of proposal for improvement in the study area and adaptation in other rapidly urbanising cities in the developing world.

\section{Scope Of Study}

The State is located approximately between latitudes $6^{0} 22^{\prime} \mathrm{N}$. $-6^{0} 42^{\prime} \mathrm{N}$ of the Equator and between Longitudes $2^{0} 42^{\prime} \mathrm{E}-4^{0} 20^{\prime} \mathrm{E}$. It has an approximate size of 3,577 square kilometres (Balogun, Odumosu and Ojo $1999 \mathrm{p} 1$ ). It is straddled from the northern boundary to the east by Ogun State and Republic of Benin to the west. The southern limit is marked by about 180 kilometres of the Atlantic Ocean's shoreline. Twenty two percent of the State, or 787 square kilometres is made up of Lagoons and Creeks. The population density is 1,590 persons per square kilometre using the 1991 census figure of 5.68million. The figure for the State was estimated in 1998 at 11.3 million (United States Bureau of Census, 1998) and projected to be around 21.1 million by 2010 (UNDP, 2001)

The period of this appraisal starts from 1977, which is the year of the establishment of the first statutory body, Lagos State Refuse Disposal Board, charged with refuse management responsibilities under Edict 9 of 1977. The activity of the Board was initially restricted to Lagos Island and Mainland. Later the civilian administration of Alhaji Lateef Jakande by the promulgation of Law No. 8 of 1980 in Gazette No. 53 Volume 13 of $24^{\text {th }}$ July 1980 renamed the Board: Lagos State Waste Disposal Board. This paper is an 
adaptation from an earlier study (Odewumi, 2004). Other scholars that have worked on the same subject matterMunicipal Solid Waste- in the study area include: Oyewale (1997), Saka (1995) Odumosu (1995) and Olokesusi (1994), Oduwaiye (2003) Olorunfemi (2003) Filani and Abumere (1994). Oni (1999) Soneye (2004). They all recognised the seriousness of the problem of waste management in Lagos State. Their suggestions revolved around institutional and legal frameworks of operation, transportation infrastructure, fleet and logistics, cultural re-orientation and government's policy consistency.

\section{Storage Strategies}

The first storage point of solid waste is at the generation spot. In Lagos State most of the domestic solid wastes are stored in nylon bags, sacks, baskets, cartons, drums, and buckets. The daily production is usually kept in any of the above containers until they are moved outside / emptied into a bigger container or to community dumpsites. In the rural areas the latter option is usually the practice. Transporting the domestic solid waste to "Aatan" is the daily chores of kids and women. The point "Aatan" is the food basket of domestic pets like chickens, dogs, goats, and pigs. The result is that at the end of the day only a small proportion of the whole daily wastes remain. The left over usually consists of non-edible materials. The organic parts usually form natural manure that is often dug up to nourish garden vegetables and plants. However, it must be mentioned that the changing composition of solid waste in favour of non-biodegradable items meant that the community dumpsites are growing bigger with less being available as manure. For instance nylons are now being used for food packaging as against the traditional practice of leaf wrappings. There is therefore an urgent need for more focused study on this aspect of the changing nature of waste composition. Appropriate method of handling should be evolved so as not only to ameliorate its negative environmental and health impacts but possibly convert them to resources.

Within the metropolis there is hardly any fallow land to be used as community dumpsites. Instead, road junctions, road divides, bus stops, public school compounds, canals and drainages are usually converted for this purpose. The better practice is when drums and other containers like the Waste bags are placed outside or by the boulevard expecting that they will be picked up by any of the various collection agencies. The waste storage practice at the point of generation is of paramount importance for efficiency in the two subsequent processes of collection, transportation and indeed the entire waste management system. When most of the wastes are in loose form, longer time is required to scoop them up compared with when they are neatly packaged in bags or relevant containers. Neatly packed wastes are easily picked up and thrown into the vehicles by the waste collectors.

\section{Bagging}

Bagging refers to the storage of solid waste at the point of generation usually in bags. This was first introduced by Lagos Waste Management Authority (LAWMA) in the 80's. It was re-introduced by Tinubu's administration and supplied free of charge in order to promote solid waste bagging culture. This has been observed not only to make waste storage hygienic but also to make waste collection a lot faster. The initial success, however, has waned. The problem that must be solved before this practice could take root is to get it effectively distributed. Currently the approach adopted does not get the material down to most households; only highbrow districts get these bags. In order to achieve sustainability in the provision of the bags it is here suggested that the state government should sell it at a subsidised price and make available like all other nylon bag This will make the bags quite affordable and available like the smaller nylon/"Ghana-must-go" bags that could be purchased from any trader and street hawkers in the State.

\section{Sorting And Storage}

One important coterminous aspect of storage is sorting at the point of generation. In Lagos there is very little attempt at sorting solid waste. All the solids, glass, Iron, leather, paper, food, clothing items etc are usually dumped together. This naturally contrasts with the highly desirable practices of reduce, re-use and re-cycle. In Metro Manila for instance it has been reported that the council of Women Balikatan Movement, a nongovernmental organisation of 20,000 women, has been recycling dry household wastes back to the factories where they are used as secondary materials in the 21 villages of San Juan, Metro Manila, Philippines. (Gate: 1997) The sorting programme has to do with sorting of garbage in the kitchen into wet (animal and food wastes) and dry (paper, plastics, bottles, tin cans, rubber slippers, bottle caps, metals) waste. The wet wastes are collected by the government agency while the dry ones are collected and paid for by the programmes "ecoaides". In household, sorters can approach the buy-back centres where they collect money in return for the recyclables. In turn, government provides the buy-back centres with financial support by paying for every tonne of waste being demonstrated to be recycled back to industry and hence saved from the land disposal. This is common in New York (US) Tokyo (Japan) and most cities of the developed countries. This aspect has not received any attention in the waste management strategy of the Lagos State. 
It is therefore suggested that for efficient overall waste management, sorting at the source should be made obligatory and rewarding. In some of the advanced cities mentioned earlier households are required to have four or more waste bins in the house for different types of waste. This should be inculcated among the Lagos residents. These could have different colours for instance Black bags for food and other biodegradable waste, Blue for plastics and Brown for glass and metals. This will assist even the scavengers in their recovery activities, reduce the total volume of the waste and provide jobs as well as financial gain for all waste disposal management stakeholders.

\section{Refuse House Storage}

This is a solid waste storage device introduced by LAWMA in the 80 's. Forty of them were constructed in areas of high refuse generation. They serve as a temporary community dumpsite or mini-transfer loading station from where the relevant agency will collect them and transport them to the landfill sites. All the structures have been sold to private individuals who have now converted them to uses other than waste handling. The decision to sell off these structures appears, to this author, not to be well considered. The refuse storage houses served as community dumpsites where residents can dump their wastes not far from their houses. In waste disposal, the proximity of the dumping point is a great factor in citizens' observance of rules against indiscriminate dumping. The immediate effect of this wrong decision is the emergence of waste along the highways median. This also turns the Cart-pushers into waste dispersals because they do not have a place nearby in the community to dump their daily takings. A major reason adduced for the sale of the houses was that the residents do not dump the refuse neatly into the storage house. A well coordinated enlightenment programme and minimal enforcement could have corrected this. It is hereby strongly recommended that the state government should buy back this structure and sublet them to the newly licensed mega-waste collectors to manage. Alternatively they could be assisted to buy it directly if the state or local government will prefer not to inject more funds into this aspect of waste management. The Private Sector Participants (PSP) will be too willing to acquire the houses.

\section{Periodic Dump Storage}

This is a practice whereby on selected days the entire community is expected to bring out all their solid waste and conduct general cleaning. The federal government of Nigeria through the Environmental Sanitation Decree No 2 of 1985 made it mandatory that every last Saturday of the month between 7.00 am and 10.00 am should be utilised to clean up the environment. The wastes collected from the above exercise are dumped at the road junctions and some designated community dumps. The volume of wastes normally increase so dramatically on this day that the collection agencies are usually unable to remove them. Hence, most of it usually found their way back to gutters and the drainages in Lagos State. Another major problem is that most of the wastes are in loose dumps, which usually requires more time to collect. There is normally no attempt at sorting. This practice was cancelled by the Obasanjo's civilian administration with the explanation that the practice of cleaning one's environment should be voluntary and habitual not decreed and that it should be inculcated through persuasion and enlightenments. Lagos and many other states like Oyo and Ondo have reverted to this method for cleaning which is usually referred to as environmental sanitation day. Initially in Lagos state the traders are expected to clean their environment every Thursday morning $7.00 \mathrm{am}$ to $10.00 \mathrm{a}$ am. Later the end of the month's Saturday sanitation was re-introduced towards the end of 2003 to improve the general environmental condition of the state.

It has been observed that setting aside periods for environmental sanitation does not necessarily translate to a cleaner environment and it does not promote a better waste management practice. In many instances when the wastes are brought out on these days to the periodic dumpsites, they remain there until they are washed into the drains because the logistics for collection are often unable to cope with the volume of waste brought out for collection. It is the opinion of this author that this periodic sanitation day should be cancelled. It is a waste of time and serious disruptions of people's social and productive life. This is currently more so because they are no longer held on the same Saturday across the country as it was the practice initially. Most travellers from other states coming to Lagos just run into the programme and are forcibly delayed or sometimes arrested at the state boundaries. A veritable source of corrupt earnings for the Kick-Against- Indiscipline (KAI) brigade. It is a "Pharisecal" (outward pretence to cleanliness) display of commitment to clean environment by the state governments. Most countries with efficient waste management system and clean environment do not have special days for cleaning. The focus should be to make it a daily routine by the residents. The role of the government is in facilitating the process with appropriate infrastructural, institutional and legal framework. 


\section{Collection Strategies}

There are several solid waste collection techniques many of which have been adopted and jettisoned in Lagos State. Collection strategies are usually designed to suit the socio cultural and technological background of the society. Some of these are examined.

\section{Bell Ringing Collections}

This is a method whereby waste collection truck will ring a bell or blares its horn to announce to the community its arrival for solid waste collection. The residents, thus alerted, will bring out their household wastes and dump it directly into the truck. Although any open back truck or tipper could be adapted, LAWMA was using rear loading garbage packers, manned by a driver and one crewman. The vehicles observe scheduled routes to arrive at given location at a particular time. This method is no longer in use. Bell ringing method is one of the fastest and most tidy ways of collection. First it requires minimal crew to supervise the dumping. Secondly as the name implies, bell-ringing collection does not require that garbage be set out on the roadside or special community dumpsite for collection. Third, it saves the time and the energy it usually takes the crew to scoop waste from ground to load it.

However the limitations of this method are that routing must be done to coincide with the time residents or their servants are likely to be at home to bring out the garbage. Hence the demographic characteristics and activities must be understood. When the traffic is chaotic and unpredictable the residents may not be able to keep the stinking waste inside the house, hence they will dump it on the street. This method requires regularity and punctuality that is not a common feature of social services in Lagos State in particular and Nigeria in general. In addition to the factors of regularity and punctuality there must be capacity equalisation between the volume of waste being generated and the vehicles. A condition of inadequacy will breed frustrations and the residents will lose confidence in the service. This problem is compounded by absence of database to predict accurately the volume of waste expected from a given area/ route. Even where the data are available the city's growth rate is such that forecasts and projections are rubbished as soon as they are made.

Much as this method recommends itself in terms of efficiency and reduced operational cost, it is our view that it could only be adopted in small contiguous and fairly homogeneous community with good accessibility and vehicular circulation. Some of the Housing Estates located on the periphery of the metropolis (Iba, Iyana Ipaja, Agege, Ogudu) could be serviced with this waste collection method. Also it is very appropriate for market areas, whether day or night. The vehicle team will be sure to meet the marketers in situ. A little token should be approved for the PSP to collect from the marketers for specific basket/bag/plastic size.

\section{Door-To-Door Collections}

When residents place their waste by the street or by their door, the waste collectors are required to pick these up from one household to the other, hence the name door-to-door. This is a technique adopted and used extensively by LAWMA for Lagos State. It is similar to the operation strategy of the Highway Managers in the collection of waste along the major road arteries in the state The mode of operation is usually carried out by a seven-man crew working behind a rear loading packer and working on one side of the road at a time. The sevenman crew consists of a driver, an inspector, a foreman and four packers. The inspector determines which site should be packed immediately and which should be left for the bulk loading by mechanical packers. He is the overall boss of the team. The foreman supervises the actual physical operation of packing and loading of the garbage and the tipping at the dumpsites by the four-crew men. The rate of collection is dependent on the rate of waste generation. LAWMA's frequency ranges from three to seven times per week. The crewmen work eight hours per day but collect overtime for extra-hours put in, which is very frequent.

The method has a lot to recommend itself. The residents are not required to be around before their wastes are collected; they only need to place it in a conspicuous point or a local designated point along the highway median for the Highway Managers. The crew tends to master their route and can therefore get round it in the most efficient way because they can easily predict the rhythm of the traffic. Unnecessary U-turns are eliminated except at the dead end of the roads. This method makes it easier to develop statistical base for logistic route planning and adequate capacity to be deployed. More importantly, for Lagos, where traffic is very chaotic, night collection is possible and often adopted with this method.

The limitations of this method are equally numerous and should be addressed before the method is adopted wholesale. First many residents do not tuck-in their garbage properly into the drum. According to the field estimates of LAVINA (1992.p10):

An estimated $40 \%$ of waste is set out in old drums left permanently on the boulevard and an estimated $45 \%$ is set out loose. The rest of the waste that is set out for pick-up is in regular garbage cans or bags, or in baskets, boxes, kerosene cans, etc. No standards apply and no requirement exists to store garbage in standard sanitary way. 
The State government's effort at providing residents with free bags reduced the proportion of the loose waste until the effort waned. About $60 \%$ of the solid wastes by the roadside are still in loose form, which makes it a lot more time consuming for collection. Even those properly stacked in drums are usually heavy. In some instances, crewmembers experience difficulties in lifting them up for tipping into the rear loader.

Total effect of these limitations is that it makes collection process slow and inefficient. For LAWMA's crew the rated efficiency of the method is 1.6tonnes/man/day (Resource Consult, 1996.p 98). Field sample of this study is about the same for LAWMA but 2.0/tonnes/man/day for the Private Sector Participant (PSP) operators. Even at this rate, given an estimated generation rate of 7000 tonnes per day, this technique will require about 3,500 hands per day to remove the waste generated.

In adopting this method therefore it is suggested that crewmen should be reduced to not more than five: a driver, a foreman and at most three collectors. Also there should be enlightenment campaign by the government in order to generate awareness on the importance of packing wastes in portable bags tied up. This crew can attain greater efficiency if allowed to work at night when the traffic is completely free and the packers are likely to work more conscientiously since there will be no passers by to exchange pleasantries and no relative or friend to dodge from.

\section{Bulk-loading collection}

This method becomes mandatory when according to Odumosu (1995) "refuse become mountains" within the metropolis. This is usually as a result of failure in the regular collection method. It then becomes imperative to deploy a method that can remove the backlog quickly and in large volume. This is usually a roving three-man team from the Zonal depots equipped to load mechanically with a pay loader and open tipper.

The advantage of the method is that it offers a back-up to assist any other method which could not meet up with the rate of waste generation in its area of coverage. This may be as a result of seasonal increase in generation, for example during festivals like "Ileya" or Christmas when there could be large increase in consumption or influx of large population. This also occurs during the environmental sanitation days, which have been mentioned earlier. Bulk loading is usually adopted to evacuate the large quantity of waste being brought out on such days. Although national environmental day has been cancelled, sanitation days are still being observed in Lagos State and bulk loading is the usual way of disposing the periodic wastes.

The major limitation is that many areas not linked by roads are not accessible to the tipper and the pay loader. Also the overhead cost tends to be higher and the improper maintenance culture often leads to frequent breakdowns of many of these vehicles. In the absence of technological base to support the maintenance, the vehicles often lie idle for months due to lack of spare parts. Also the cost of purchasing equipment for this type of collection is too high for the average PSP operator. The government should purchase these and sublet it to them on day-rental basis in order for them to clear emergency waste backlogs. Another option is for the government to provide loans or facilitate their access to loan, individually or collectively for the acquisition of these expensive machineries.

\section{Bin Collection}

This is also a mechanical method of collection. There is a container (bin) designed like a small lowlevel trailer or a truck chassis and the Dinosaurs: the collection vehicle. The bins are strategically placed and the residents are expected to dump their waste carefully and neatly into them day and night. The containers are either the smaller mammoth bins lids or the larger open Dinosaur bins. Once the bins are full their collections are made by just hooking the bins with truck chassis specifically designed for that purpose and it is immediately replaced with an empty bin brought by the same vehicle. The technique requires a crew, of one driver and two "Dino" mates. The duty of the two Dino mates is to assist the driver in loading/off loading processes and pulling tarpaulin across the tops of the full bins before they are driven away so as to prevent scattering along the way.

This method is the fastest methods of waste collection. If the residents observe their own aspect of the procedure by dumping the waste carefully and neatly into the bin it will save the crew the labour of having to scoop the waste into the vehicle. But the trouble is that many residents hardly observe this simple rule; instead the wastes are usually dumped indiscriminately thereby forcing the crew to perform tasks that were not meant for them. Moreover the crew then becomes inadequate for the added tasks. The process is thus slowed down considerably. In order to make this method work there must be proper enlightenment for the residents on their own responsibility. As in the case of the equipment for bulk loading the issue of cost should be addressed to help the PSP who may lack the funding capacity to purchase the bins and the Dinos. Definitely this is the best collection method. The PSP should be encouraged to adopt it. 


\section{Towing Of Abandoned Vehicles}

There are several organisations that are mandated to handle the collection of abandoned vehicles. Federal Road Safety Corp (FRSC), the Police, Ministry of Environment and physical Planning, Lagos State Transport Agency (LASTMA) Local Government officials and LAWMA. Abandoned/ accident vehicles constitute a very significant part of solid waste that needs to be disposed. Appropriate vehicles are deployed to tow the offending or accident vehicles to the designated locations. When LAWMA was given this task in the early 80 's, Lagos was littered with over 9, 000 accident and abandoned vehicles. The authority removed these from the footpaths, roadsides and open spaces in the State. They were crushed at Eric Moore Car crushing plant, which is yet to be repaired since it broke down in 1985 .

Later the federal government directed that the accident vehicles be removed by the Police to their stations nationwide. Part of the objectives of the federal government then was to present examples of results of careless driving and non-observance of safety rules on the highway. Many police stations till now are more like accident vehicle museums. This in many cases in Lagos State is creating traffic bottlenecks in the state. This policy should be discontinued forthwith. Spaces should be created for these vehicles outside the metropolis. There should be policy statement as to how long the vehicles could be kept in these yards before they are crushed, sold in parts or disposed off in whatever form.

\section{Corpse Removal And Street Cleanings}

All the departments that have undertaken this task testified that it is more tedious than is generally assumed. Overtime the number of corpses found on the roads has increased tremendously. From the innocent victims of hit and run drivers to the increasing numbers of suspected armed robbers meted with instant justice of roasting. And anytime there is political and social upheaval/ ethnic clash, the street is often littered with corpses. The corpses cannot be disposed in the same way as the other solid waste in the Landfill but in the public mortuaries and cemeteries that are already congested. Our suggestion in this regard is that the State government should conclude its cremation project, so that corpses could be decently, timely and hygienically disposed of. The cemeteries in the State can no longer cope with the volume of unclaimed corpses found on Lagos Streets everyday.

\section{CONCLUSION}

Municipal Solid Waste management problem is a perennial problem that ad-hoc strategies can not solve. As long as there is life, productive activities and consumption waste will continuously be generated. The problem is aggravated by increasing rate of urbanisation. Two aspects of the overall management of the problem are examined in this paper: Storage and collection strategies. The common storage strategies at the point of generation in Lagos state include placement in drums, bags, baskets, cartons, buckets and plastics. Beyond this point there were Refuse Houses, Community Dumpsites, Junctions, Highway median and drainages. It is recommended that Refuse Houses that were sold off be re-purchased for the use of the PSP operators. This will provide nearby temporary storage for high waste generating areas of the metropolis without open spaces for such.

Furthermore it is highly recommended that sorting of waste be done at the point of generation in the household. This will promote waste reduction, re-use and re-cycling. It will also generate income and provide jobs as well as raw materials for some industries. Colour code should be introduced into the waste bags for different types of wastes. The state government should supply the bags at subsidised price to the residents so that it will be available and affordable.

Waste collection methods include: Bell Ringing, Door-to-Door, Highway traverse, Bulk loading, Bin Collection, Towing of abandoned or accident vehicles and corpse removals. All of them are appropriate for specific zones and demographic make up. It is important to understand the population to be served before a collection method is adopted. Since the state government is increasing the role of the PSP in waste managementa step in the right direction-appropriate infrastructural, institutional and legal framework should be constantly fine-tuned to support the private sector participants especially in the area of cost recovery. Also continuous public enlightenment programme is mandatory, so that the citizens will be properly informed of their privileges and responsibilities within the policy framework that is driving the whole management system.

\section{References}

[1]. Balogun,Y. Odumosu, T. \& Ojo, K (1999) Lagos State in Maps. Rex Charles publication, Ibadan.

[2]. Filani, M. O. \& Abumere S(1986) "Forcasting Solid Waste Magnitude for Nigeria Cities" In Adeniji, E. O. and I. B. Bello-Iman (eds) op.cit. pp. 193-208.

[3]. Gate (1996) ttp://www.oneworld.org/globalprojects/humcdrom. Oepen Manfred (author) "Scavengers and Recycling in Indonesia "Humanity Development Library

[4]. LAVALIN (1992) "Organisation Development and Waste Management System Project' a report prepared by LAVALIN International Inc for LAWMA, Lagos 
[5]. LAWMA (1995) "The Problems of Waste Management in Lagos State" Proposal Submitted to Petroleum (special) Trust Fund for funding assistant. Prepared by Resource Consult Ltd. 177, Kirikiri Road, Olodi Apapa, Lagos.

[6]. LAWMA (1995) "The Problems of Waste Management in Lagos State" Proposal Submitted to Petroleum(special)TrustFundforfunding assistant. Prepared by Resource Consult Ltd. 177, Kirikiri Road, Olodi Apapa, Lagos.

[7]. Odewumi. S.G (2004) “A study of Solid Waste Transportation in Metropolitan Lagos" P.hD Thesis. Department of Geography. University of Lagos.

[8]. Odumosu Tayo (1995) "When Refuse Dumps Become Mountains-Solid Waste Management in Metropolitan Lagos" in M Tesi (ed) The Environment and Development in Africa. Middle Tennese State University, U.S.A

[9]. Oduwaye Leke (2003) "Waste -Management in Lagos State: Residential Land Values and their Determinants in High Density Neighbourhoods of Metropolitan Lagos" in Social Sciences Journal of Lagos State University, Ojo Lagos, pp132-156

[10]. Olokesusi, Femi (1994) "Sustainability and Solid Waste Management in metropolitan Lagos - The Imperatives for Improvement" in Albert, I. O. et.al (eds) Ibid

[11]. Olorunfemi, Felix B (2003) Perception and Analysis of the impact of Noxious Facilities in Urban Areas: The Case of Landfills in Lagos Metropolis. A PhD thesis in the department of Geography University of Ibadan

[12]. Oni, Iyiola. (1999) "Towards a sustainable and Integrated Traffic Systems Management Policies for Nigerian Cities" unpublished paper in the Department of Geography, University of Lagos, Lagos Nigeria

[13]. Oyewale, E.O. (1997): "Framework for sustainable Environmental Planning and Management in Nigeria: Case Study of Municipal Solid Waste Management in Ibadan and Lagos Metropolises." an unpublished Ph.D. Proposal in the Department of Geography and Planning, LASU, Lagos

[14]. Saka. G. O.(1995) “A Decade of Waste Management in Lagos State: An Appraisal” A paper presented as the General Manager of LAWMA at Lagos State University's Conference on Environmental Sanitation in Nigeria to mark world Environment Day : May, 31 1995

[15]. Soneye, A. S. O (2004) "Institutional Dilemma of Urban Waste Management in Nigeria: The Lagos State Experience" in Indusrialisation, Urbanisation and Development in Nigeria 1950-1999. Adejugbe (edt) Concept publications, Lagos

[16]. UNDP (1991) Human Development Report 1991, Oxford University Press, Oxford

[17]. United Nations Centre for Human Settlements -Habitat(1989) Solid Waste Management in Low-income Housing Projects- The scope of community Participation, Nairobi, Kenya

[18]. United States Bureau of Census (1998) "50-Largest Urban Centres of the World" in Microsoft ENCARTA digital library 2002 